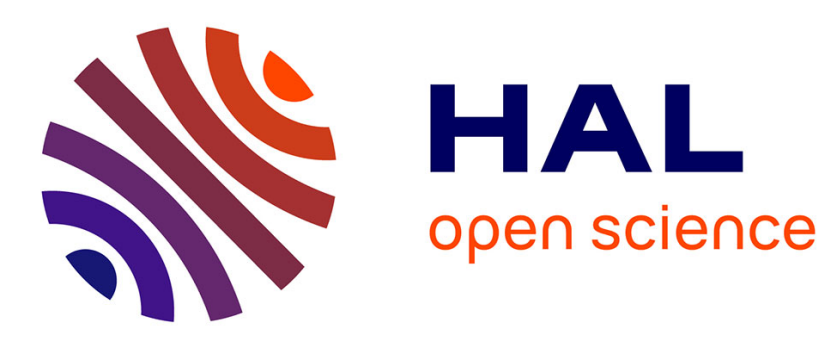

\title{
First International Summer School on Runtime Verification
}

Christian Colombo, Yliès Falcone

\section{To cite this version:}

Christian Colombo, Yliès Falcone. First International Summer School on Runtime Verification: as part of the ArVi COST Action 1402. Sixteenth International Conference on Runtime Verification, Sep 2016, Madrid, Spain. hal-01428838

\section{HAL Id: hal-01428838 \\ https://hal.inria.fr/hal-01428838}

Submitted on 6 Jan 2017

HAL is a multi-disciplinary open access archive for the deposit and dissemination of scientific research documents, whether they are published or not. The documents may come from teaching and research institutions in France or abroad, or from public or private research centers.
L'archive ouverte pluridisciplinaire HAL, est destinée au dépôt et à la diffusion de documents scientifiques de niveau recherche, publiés ou non, émanant des établissements d'enseignement et de recherche français ou étrangers, des laboratoires publics ou privés. 


\title{
First International Summer School on Runtime Verification as part of the ArVi COST Action 1402
}

\author{
Christian Colombo $^{1}$ and Yliès Falcone ${ }^{2}$ \\ 1 University of Malta, Malta - christian.colombo@um.edu.mt \\ 2 Univ. Grenoble-Alpes, Inria, LIG, F-38000 France - ylies.falcone@imag.fr
}

\begin{abstract}
This paper briefly reports on the first international summer school on Runtime Verification: Branches of practical topics rooted in theory, co-organized and sponsored by COST Action IC1402 ArVi which was held September 23-25, Madrid, Spain as part of the 16th international conference on Runtime Verification (RV 2016).
\end{abstract}

Runtime Verification $[1,3-5,2]$ is an umbrella term usually denoting the languages, techniques, and tools related to the verification of system executions against formally-specified behavioral properties. This field of research has been mainly represented by the Runtime Verification (RV) conference $^{3}$ which was held yearly for the last 16 years. As the field is growing and the techniques are becoming more and more mature, there is a pressing need in the community for documentation and lecture material to help students and practitioners entering the field, in spite of the existing (incomplete) tutorials and short overviews of the field. We foresee the organization of this summer school as one of the steps towards achieving this goal. By organizing the summer school, we wanted to build a short theoretical and practical program allowing to give in 3 days the necessary introductory knowledge to a practitioner or student entering the field.

Objectives. As the name of the summer school suggests, the summer school aimed to provide a balance of theory and practice: In the theoretical aspect, while all the core concepts were covered, participants were also exposed to cutting edge advances in the field. At the same time, the summer school was very hands-on and students followed up with practical work in the evenings so that by the end of the summer school, participants had created their own basic runtime verification tool.

For $\mathrm{PhD}$ students and researchers entering the field of RV, the school was a great opportunity to get to know other people working in the area, to meet distinguished scholars, and to establish contacts that may lead to research collaborations in the future. For people coming from industry, the school provided an exposition of the major challenges as well as possible solutions to the application of RV in industry, an exposition to the major tools, as well as the basics of RV tool-building.

\footnotetext{
3 See http://runtime-verification.org.
} 
Table 1. Programme overview - Day 1 - 23rd September

\begin{tabular}{|c|c|c|}
\hline Time & Topic & Lecturer \\
\hline 09:00 09:45 & RV overview, RV vs other verification techniques & \multirow{2}{*}{ Y. Falcone } \\
\hline $09: 4510: 30$ & Summer school Overview and manual monitoring & \\
\hline 11:00 11:45 & Monitoring with AOP & \multirow{2}{*}{ G. Pace } \\
\hline $11: 4512: 30$ & Towards monitoring specification languages & \\
\hline 14:00 14:45 & Monitoring LTL specifications & \multirow{2}{*}{ M. Leucker } \\
\hline 14:45 15:30 & Monitorability & \\
\hline 16:00 16:45 & Hands on & \multirow{3}{*}{ C. Colombo } \\
\hline $16: 4517: 30$ & Hands on & \\
\hline $18: 00$ & Optional further assistance with hands on & \\
\hline
\end{tabular}

Table 2. Programme overview - Day 2 - 24th September

\begin{tabular}{|c|c|c|}
\hline Time & Topic & Lecturer \\
\hline 09:00 09:45 & \multirow{2}{*}{$\begin{array}{l}\text { Handling data } \\
\text { in user-provided specifications }\end{array}$} & \multirow{2}{*}{ K. Havelund } \\
\hline 09:45 10:30 & & \\
\hline 11:00 11:45 & \multirow{2}{*}{$\begin{array}{l}\text { Monitoring concurrency errors: } \\
\text { deadlocks, atomicity violations, and data races }\end{array}$} & \multirow{2}{*}{ J. Lourenco } \\
\hline $11: 4512: 30$ & & \\
\hline 14:00 14:45 & \multirow{2}{*}{ Performance issues and optimizations } & \multirow{2}{*}{ G. Reger } \\
\hline $14: 4515: 30$ & & \\
\hline $16: 0016: 45$ & \multirow{2}{*}{ Hands on } & \multirow{3}{*}{ C. Colombo } \\
\hline $16: 4517: 30$ & & \\
\hline 18:00 & Optional further assistance with hands on & \\
\hline
\end{tabular}

Table 3. Programme overview - Day 3 - 25th September

\begin{tabular}{|l||l|c|}
\hline Time & Topic & Lecturer \\
\hline \hline 09:00 $09: 45$ & Design and Monitoring of Component-Based Systems & M. Bozga \\
\hline 09:45 $10: 30$ & Distributed monitoring \& monitoring distributed systems & \multirow{2}{*}{ B. Bonakdarpour } \\
\hline 11:00 $11: 45$ & Time-Triggered monitoring & D. Nickovic \\
\hline 11:45 $12: 30$ & From Monitoring quantitative properties to testing & W. Ahrendt \\
\hline 14:00 $14: 45$ & Combined Static and Runtime Verification & W. Binder \\
\hline 14:45 $15: 30$ & Bytecode manipulation for Runtime Verification & Y. Falcone \\
\hline 16:00 $16: 45$ & Runtime enforcement & A. Francalenza \\
\hline 16:45 $17: 30$ & A Theory of Monitors &
\end{tabular}


Lecturers. The following researchers lectured at the summer school:

- Prof. Wolfgang Ahrendt, Chalmers University of Technology and University of Gothenburg (Sweden).

- Prof. Ezio Bartocci, TU Wien (Austria).

- Prof. Borzoo Bonakdarpour, University of MacMaster (Canada).

- Dr. Marius Bozga, CNRS, Vérimag (France).

- Dr. Christian Colombo, University of Malta (Malta).

- Dr. Yliès Falcone, University of Grenoble (France).

- Dr. Adrian Francalanza, University of Malta (Malta).

- Dr. Klaus Havelund, NASA Jet Propulsion Laboratory (USA).

- Prof. Martin Leucker, University of Lübeck (Germany).

- Prof. Joao Loureno, Universidade Nova de Lisboa (Portugal).

- Dr. Dejan Nickovic, Austrian Institute of Technology (Austria).

- Prof. Gordon Pace, University of Malta (Malta).

- Dr. Giles Reger, University of Manchester (UK).

Program overview. The Summer School was organised over three days with a series of lectures from international experts during the day and a follow up practical session in the evening to enable the participants to incorporate the covered knowledge into their tool (see Tables 1-3). The first day covered the fundamentals of runtime verification: starting with the basic concept of what is runtime verification, moving on to instrumentation techniques, and property specification languages. The second day covered the major practical aspects of runtime verification: handling data through monitor parametrisation, monitoring concurrency errors, and performance issues of monitors. The second day ended with a session on RV tools, giving the participants time to try tools and interact with their creators. Finally, the third day covered advanced and cutting-edge research in the field with topics ranging from runtime enforcement to the combination of static and dynamic analysis, and from monitoring of distributed and transaction-based systems to low-level hardware monitoring.

Acknowledgment. We would like to warmly thank all the researchers for their lectures and all the participants to the summer school. We hope that the summer school will be continued in the future by becoming a regular event.

This summer school is based upon work from COST Action ARVI IC1402, supported by COST (European Cooperation in Science and Technology). The organizers are grateful to the COST association for sponsoring the summer school.

\section{References}

1. Colin, S., Mariani, L.: Run-time verification. In: Broy, M., Jonsson, B., Katoen, J., Leucker, M., Pretschner, A. (eds.) Model-Based Testing of Reactive Systems, Advanced Lectures [The volume is the outcome of a research seminar that was held in Schloss Dagstuhl in January 2004]. Lecture Notes in Computer Science, vol. 3472, pp. 525-555. Springer (2004) 
2. Falcone, Y., Havelund, K., Reger, G.: A tutorial on runtime verification. In: Broy, M., Peled, D.A., Kalus, G. (eds.) Engineering Dependable Software Systems, NATO Science for Peace and Security Series, D: Information and Communication Security, vol. 34, pp. 141-175. IOS Press (2013)

3. Havelund, K., Goldberg, A.: Verify your runs. In: Meyer, B., Woodcock, J. (eds.) Verified Software: Theories, Tools, Experiments, First IFIP TC 2/WG 2.3 Conference, VSTTE 2005, Zurich, Switzerland, October 10-13, 2005, Revised Selected Papers and Discussions. Lecture Notes in Computer Science, vol. 4171, pp. 374-383. Springer (2005)

4. Leucker, M., Schallhart, C.: A brief account of runtime verification. Journal of Logic and Algebraic Programming 78(5), 293-303 (may/june 2008)

5. Sokolsky, O., Havelund, K., Lee, I.: Introduction to the special section on runtime verification. STTT 14(3), 243-247 (2012) 